\title{
A PESSOA COM DEFICIÊNCIA E SUA INSERÇÃO NO MERCADO DE TRABALHO BRASILEIRO: MARCOS NORMATIVOS E AÇÕES AFIRMATIVAS
}

\author{
Rodrigo Garcia Schwarz* \\ Milena Veloso de Linhares**
}

\section{RESUMO:}

O presente artigo tem por objetivo verificar, a partir dos marcos normativos internacionais e nacionais dos direitos e das garantias das pessoas com deficiência, o propósito e a efetividade das ações afirmativas adotadas no Brasil para a inclusão das pessoas com deficiência no mercado de trabalho, em condições dignas e equitativas, especialmente a partir do disposto no art. 93 da Lei $\mathrm{n}^{\circ}$ 8.213/91. O problema consiste em verificar se, a par da proteção assegurada legalmente, as pessoas com deficiência têm sido integradas, efetivamente, ao mercado de trabalho no Brasil. O procedimento investigativo adotado é descritivo-explicativo do tipo documental-bibliográfico.

Palavras-chave: ações afirmativas; deficiência; mercado de trabalho; pessoa com deficiência; trabalho decente

\section{PERSON WITH DISABILITIES AND ITS INSERTION IN THE BRAZILIAN LABOR MARKET: NORMATIVE FRAMEWORKS AND AFFIRMATIVE ACTIONS}

\begin{abstract}
:
This article aims to verify, from international and national normative frameworks of the rights and guarantees of people with disabilities, the purpose and effectiveness of the affirmative actions adopted in Brazil for the inclusion of people with disabilities in the labor market on decent work terms, especially from the provisions of Brazilian Law $n^{\circ} 8213 / 91$. The problem is to verify that, along with legally protected protection, people with disabilities have been effectively integrated into the labor market in Brazil. The investigative procedure, of documentary and bibliographic type, is descriptive and explanatory.
\end{abstract}

Keywords: affirmative actions; decent work; disabilities; labor market; person with disabilities

\section{INTRODUÇÃO}

No presente artigo, busca-se verificar, a partir dos tratados internacionais ratificados pelo Brasil na defesa dos direitos e das garantias das pessoas com deficiência, e das disposições constitucionais e legais brasileiras, o propósito e a efetividade das ações afirmativas adotadas

\footnotetext{
* Professor Permanente do PPGD do Centro Universitário FIEO - UNIFIEO, Doutor em Direito e em História Social. Líder do Grupo de Pesquisa (DGP-CNPq) Dimensão Material e Efetivação Jurisdicional dos Direitos Econômicos, Sociais e Culturais: Relações de Trabalho e Seguridade Social. E-mail: rgschwarz@ gmail.com.

** Mestranda do PPGD da Universidade do Oeste de Santa Catarina - UNOESC. Membro do Grupo de Pesquisa (DGP-CNPq) Dimensão Material e Efetivação Jurisdicional dos Direitos Econômicos, Sociais e Culturais: Relações de Trabalho e Seguridade Social. E-mail: milenalinhares94@gmail.com.
} 
no Brasil, quanto à inclusão das pessoas com deficiência no mercado de trabalho, em condições dignas e equitativas, sobretudo a partir do disposto no art. 93 da Lei $\mathrm{n}^{\circ}$ 8.213/91, que estabelece, para a empresa com 100 (cem) ou mais empregados, uma quota mínima de preenchimento dos respectivos cargos com beneficiários reabilitados ou pessoas com deficiência, habilitadas.

Assim, tem-se como objetivo analisar de modo geral as normativas internacionais ratificadas pelo Estado brasileiro e a legislação nacional, sua abordagem acerca dos direitos e das garantias das pessoas com deficiência e sua correspondência com as ações afirmativas adotadas no Brasil, em especial à vista do disposto no art. 93 da Lei no 8.213/91.

O problema consiste em verificar se, a par da proteção assegurada legalmente aos seus direitos e às suas garantias, as pessoas com deficiência têm sido integradas, efetivamente, ao mercado de trabalho no Brasil.

O procedimento investigativo adotado é descritivo-explicativo do tipo documentalbibliográfico.

\section{PESSOA COM DEFICIÊNCIA: MARCO NORMATIVO E DEFINIÇÃO}

$\mathrm{Na}$ luta social histórica de grupos marginalizados por reconhecimento de igualdade em direitos, dignidade, liberdade e justiça social, verificam-se, contemporaneamente, novos rumos e avanços, pelos quais se ampliam os direitos à igualdade e a melhores condições para uma vida digna para todo o ser humano, a par da manutenção de alguns preconceitos que se opõem à plena igualdade. O ser humano ainda não trata outro ser humano como igual, de forma generalizada, tanto assim que juridicamente imposta, inclusive por convenções e tratados internacionais, a garantia ao respeito e à proteção daqueles que tradicionalmente vivem à margem da sociedade e que demandam, para a sua plena integração a esta, ações afirmativas. Nesse quadro, está a pessoa com deficiência.

Nesse contexto, um marco na história dos direitos humanos é a Declaração Universal dos Direitos Humanos, proclamada em 1948 pela Assembleia Geral das Nações Unidas. A Declaração Universal aborda questões essenciais à pessoa, como o direito à vida, à liberdade, à segurança pessoal, à liberdade de palavra e de crença e à dignidade, reforçando a valorização universal do ser humano e a sua igualdade de direitos em termos básicos, garantindo a todo ser 
humano gozar dos seus direitos e das suas liberdades, sem qualquer distinção, de raça, cor, idioma, sexo, religião, opinião política, riqueza, nascimento ou outra condição.

Segundo Casado Filho (2012), assim, a partir da Declaração Universal os direitos humanos passam a ter voz efetiva no plano internacional. A Declaração Universal, reforçada pela Declaração de Direitos Humanos de Viena de 1993, requer, segundo Piovesan (2011), em uma perspectiva dos direitos humanos para as pessoas com deficiência, ações e ajustes específicos para que possam disfrutar de todos os direitos, nos serviços públicos e no âmbito privado, para que possam ser parte integrante e ativa da sociedade, inclusive pelo trabalho, garantindo-se, a elas, uma vida plena e justa.

A inclusão das pessoas com deficiência e o reconhecimento de seus direitos foi reforçada, no Brasil, pelo Decreto $n^{\circ} 3.956 / 2001$, pelo qual o Brasil adotou duas convenções internacionais, a Convenção no 159 da OIT e a Convenção de Guatemala.

Outro grande passo em direção às garantias dos direitos das pessoas com deficiência foi a adoção da Convenção sobre Direitos das Pessoas com Deficiência, das Nações Unidas, ONU, primeiro tratado internacional de direitos humanos recepcionado pelo Brasil com status hierárquico de emenda constitucional $\left(\S 3^{\circ}\right.$ do art. $5^{\circ}$ da Constituição, incluído pela Emenda Constitucional $n^{\circ}$ 45, de 2004), complementado pela Lei Brasileira de Inclusão da Pessoa com Deficiência (Estatuto da Pessoa com Deficiência) - Lei no 13.146/2015.

A Declaração Sociolaboral do Mercosul trata da não discriminação da pessoa com deficiência e também do seu direito ao justo trabalho, em condições de respeito à dignidade e à igualdade. Embora tal declaração não possua efeito vinculante pleno, inserindo-se no âmbito do que se denomina soft law, está integrada materialmente ao núcleo duro da Constituição, restando os direitos nela enunciados uma extensão lógica de direitos e garantias enunciados constitucionalmente (REZENDE, 2002).

O Pacto de San José da Costa Rica - Convenção Americana sobre Direitos Humanos -, no seu art. $1^{\circ}$, trata do comprometimento dos Estados-partes no respeito dos direitos e das liberdades nele reconhecidos, garantindo também o seu livre e pleno exercício a qualquer indivíduo que se encontrar no respectivo território, sem nenhum tipo de discriminação, qualquer que seja a sua forma.

Ademais, afirma que pessoa é todo ser humano, tratando, para toda a pessoa, do direito à vida, à integridade pessoal, à liberdade pessoal, à proteção da honra e da dignidade. E, em seu art. 41, o Pacto trata da obrigação de progressividade assumida pelos Estados-partes, de 
promover medidas pertinentes à observância e à defesa dos direitos humanos.

O Protocolo de São Salvador, adicional à Convenção Americana sobre Direitos Humanos, reafirma o propósito de consolidar no continente americano um regime de liberdade pessoal e de justiça social, cristalizado essencialmente na condição de respeito aos direitos do ser humano em sua plenitude.

Em todos esses marcos normativos essenciais, reconhece-se e afirma-se a dignidade humana, sendo todos aplicáveis à pessoa com deficiência.

Em seu art. $2^{\circ}$, a Convenção sobre Direitos das Pessoas com Deficiência traz a definição de discriminação por motivo de deficiência como toda e qualquer diferenciação, exclusão, restrição que esteja baseada na deficiência do indivíduo com o objetivo de impedir ou impossibilitar o reconhecimento ou o desfrute ou, ainda, o exercício em igualdade de oportunidades com as outras pessoas dos direitos humanos e das liberdades fundamentais, em todas as esferas, sejam elas políticas, sociais, econômicas, culturais ou qualquer outra.

Pessoas com deficiência, assim, são aquelas que têm impedimentos de natureza física, intelectual ou sensorial, os quais, em interação com diversas barreiras, podem obstruir sua participação plena e efetiva na sociedade com as demais pessoas.

Ao tratar do tema, Seda (2017, p. 22) afirma que as deficiências: "son problemas en las funciones fisiológicas o en las estructuras corporales de una persona. Pueden consistir em una pérdida, defecto, anomalía o cualquier otra desviación significativa respecto a la norma estadísticamente establecida".

A Convenção sobre Direitos das Pessoas com Deficiência reconhece que a deficiência é um conceito em evolução e que a deficiência resulta da interação entre pessoas com deficiência e as barreiras atitudinais e ambientais que impedem sua plena e efetiva participação na sociedade em igualdade de oportunidades com as demais pessoas.

A condição da deficiência pode ser entendida com base em duas concepções principais: o modelo ou paradigma médico e o modelo ou paradigma social.

O modelo médico passa pelo foco na necessidade de reabilitação da pessoa com deficiência, e chegou à esfera legislativa brasileira com a Lei 8.213/91, que incluía a prestação de serviços de reabilitação profissional como uma de suas obrigações na perspectiva da integração da pessoa com deficiência; a partir da Constituição de 1988, contudo, e sobretudo a partir dos anos 1990, transitou-se para um modelo social, da integração para a inclusão, que se caracteriza por uma sociedade que deve se preparar para oferecer condições que viabilizem, por 
qualquer pessoa - inclusive a pessoa com deficiência -, o seu pleno desenvolvimento e o pleno exercício de sua cidadania.

É por isso que a Convenção sobre Direitos das Pessoas com Deficiência define a deficiência de modo abrangente, levando em conta o ambiente social e o momento histórico, além da diversidade existente entre as próprias pessoas com deficiência.

Segundo Sassaki (2010), estamos, no Brasil, vivenciando uma fase de transição entre o modelo médico (integração) e o modelo social (inclusão), o que explica a coexistência desses processos. O que se espera, com a vigência da Convenção sobre Direitos das Pessoas com Deficiência e da Lei Brasileira de Inclusão, que a concretiza, é que a inclusão se fortaleça cada vez mais, minimizando posturas e conceitos que ainda traduzem preconceitos e estereótipos.

\subsection{DIREITO AO TRABALHO DIGNO}

A Constituição brasileira de 1988, em seu capítulo destinado a garantias e direitos fundamentais, prevê uma série de proteção à pessoa humana, tratando todos com o mesmo merecimento, cada um na medida de suas necessidades. Por outro lado, o valor social do trabalho e a busca do pleno emprego são marcos estabelecidos na Constituição, inclusive quanto à pessoa com deficiência, observados, em especial, os termos da Convenção sobre Direitos das Pessoas com Deficiência e da Lei Brasileira de Inclusão, que a concretiza.

A Declaração Universal dos Direitos Humanos, especificamente, deixa claro que o ser humano possui direito ao trabalho, ou seja, à livre escolha de emprego em condições justas e favoráveis de ambiente de trabalho, com igual remuneração por igual trabalho.

Objetivando a inclusão das pessoas com deficiência no mercado de trabalho, a Lei $\mathrm{n}^{\circ}$ 7.853/89 dispõe sobre o apoio às pessoas com deficiência, sua integração social, e sobre a Coordenadoria Nacional para Integração da Pessoa Portadora de Deficiência, com o fim de assegurar o pleno exercício de direitos individuais e sociais das pessoas com deficiência.

Em 1991, a Lei $\mathrm{n}^{\circ}$ 8.213/91 tratou de estabelecer, para a empresa com 100 (cem) ou mais empregados, uma quota mínima de preenchimento dos respectivos cargos com beneficiários reabilitados ou pessoas com deficiência, habilitadas.

Seda (2017), ao abordar questões acerca dos tratados internacionais sobre a pessoa com deficiência, afirma que em todos os documentos existem referências diretas aos princípios da igualdade e da não discriminação e que os Estados-partes têm a obrigação de promover ações necessárias para que seja eliminada qualquer forma de discriminação ou exclusão que as 
pessoas com deficiência possam sofrer, para que elas tenham garantidos todos os direitos inerentes à pessoa humana, inclusive o trabalho.

O Pacto Internacional de Direitos Econômicos, Sociais e Culturais, assim, por exemplo, inclui também o direito ao trabalho digno e à justa remuneração, o direito à educação, o direito a um nível de vida adequado, entre outros. Em seu art. $6^{\circ}$, dispõe que os Estados-partes reconhecem o direito ao trabalho, o que significa que toda pessoa tem o direito de ter possibilidades de sustento por meio de um trabalho de sua livre escolha ou aceitação, bem como, que os Estados devem tomar medidas para assegurar esse direito.

O Protocolo de São Salvador, em seu art. $6^{\circ}$, trata do direito ao trabalho, afirmando que todos os indivíduos possuem direito ao trabalho, à oportunidade de obter meios para que tenham uma vida digna por meio de seu trabalho formal, de livre escolha. No que diz respeito às pessoas com deficiência, retrata também o comprometimento dos Estados-partes na garantia da efetividade do trabalho e do pleno emprego, entre outros.

A Lei $n^{\circ} 13.146 / 2015$, de inclusão da pessoa com deficiência, que busca abranger o maior número possível de pessoas com incapacidade, em seu art. $1^{\circ}$ dispõe que a lei é destinada a assegurar e a promover, em condições de igualdade, o exercício dos direitos e das liberdades fundamentais por pessoa com deficiência, visando à sua inclusão social e cidadania.

O estatuto da pessoa com deficiência tem por base a Convenção sobre os Direitos das Pessoas com Deficiência e seu protocolo facultativo, ratificados pelo Congresso Nacional.

As Convenções no 111 e 159 da Organização Internacional do Trabalho - OIT tratam da erradicação da discriminação em matéria de emprego e profissão. A Convenção no 159 , em especial, sobre Reabilitação Profissional e Emprego de Pessoas Deficientes, trata da inclusão da pessoa com deficiência ao mercado de trabalho, dispondo, nesse sentido, que pessoas com deficiência são todas as pessoas cujas possibilidades de obter e conservar um emprego adequado e de progredir no mesmo fiquem substancialmente reduzidas devido a uma deficiência de caráter físico ou mental devidamente comprovada.

Mais uma vez, são ressalvados os direitos ao trabalho justo e digno às pessoas com deficiência e aos demais trabalhadores com igualdade de oportunidades e tratamento, observado o tratamento não discriminatório.

\subsection{DIREITO À IGUALDADE E À PROTEÇÃO}

Acerca dos direitos humanos de igualdade e proteção, os tratados internacionais atuam sobre todos os países de forma que se vinculam para assegurar de todas as formas o respeito e 
a garantia de proteção aos direitos humanos.

Ao tratar da concepção de igualdade, Lobato e Santos (2003) expõem que, para tal, se deveria levar em consideração os comportamentos inevitáveis da convivência da sociedade e das comunidades - como no caso da discriminação - e não apenas questões de cunho fático e econômicas. Ainda, quanto às desigualdades existentes na sociedade, que as mesmas sejam tratadas de forma desigual, cada uma na medida de sua necessidade, para que seja evitada a perpetuação de situações que promovam a desigualdade social de determinados grupos ou de determinadas pessoas.

A Convenção sobre Direitos das Pessoas com Deficiência reconhece a importância da acessibilidade aos meios físico, social, econômico e cultural, à saúde, à educação e à informação e à comunicação, para possibilitar às pessoas com deficiência o pleno desfrute de todos os direitos humanos e liberdades fundamentais.

Nesse sentido, Linhares (2002, p. 85) indaga: "Noutras palavras, para que servem efetivamente as liberdades individuais se a pessoa se encontra escravizada à miséria ditada pelas condições sociais das profundas desigualdades? Disso, pode-se refletir no seguinte sentido: criam-se as normativas legislativas para assegurar que sejam respeitados os direitos mínimos do ser humano em todos os sentidos de sua vida; porém, torna-se evidente a necessidade de criar normas para proteção de determinados grupos sociais, que estão à mercê de uma sociedade que discrimina, julga, exclui e é fechada para aquilo que considera e rotula como fora da normalidade.

Em seu art. 18, intitulado "proteção de deficientes”, o Protocolo de São Salvador deixa claro que os Estados devem observar a garantia de direitos às pessoas com deficiência. Ressalta que todas as pessoas que tenham diminuição de suas capacidades físicas ou mentais têm direito de receber atenção especial, objetivando que elas tenham o máximo de desenvolvimento de sua personalidade. Destaca, ainda, que os Estados-partes estão comprometidos em adotarem medidas para que assegurem o pleno direito às pessoas com deficiência, de forma a executarem programas destinados exclusivamente às pessoas com deficiência, incluindo-se programas trabalhistas adequados às suas possibilidades, promoção de formação especial às famílias das pessoas com deficiência, inclusão prioritária em seus planos de desenvolvimento urbano, com soluções específicas para as necessidades desses indivíduos, a atuação na promoção para a formação de organizações sociais nas quais as pessoas com deficiência possam desenvolver uma vida plena. 
Tem-se então que é preciso voltar o olhar para essas pessoas, como seres humanos que são, promovendo um bem estar social, por meio de medidas e meios adequados, executar programas destinados a que sejam desenvolvidas as suas capacidades físicas ou mentais, inclusive em programas de trabalho adequados as suas possibilidades, contribuir para que as famílias sejam preparadas para que possam tem uma melhor convivência com o familiar deficiente, realizar projetos com vistas ao desenvolvimento pessoal, familiar e profissional de maneira plena na sociedade.

Conforme Silva (2005), o Estado brasileiro tem um divisor de águas na Constituição de 1988, que traz em seu texto, no art. $5^{\circ}$, a inviolabilidade dos direitos fundamentais, como direito à vida, à liberdade, à igualdade, a segurança, entre outros.

O fato é que, apesar de declarações, convenções, pactos, protocolos e tratados assinados e ratificados pelos Estados-partes, injustiças ainda acontecem todos os dias no mundo inteiro. Contudo, abusos e desrespeitos contra os direitos humanos não podem e tampouco devem ser tolerados, mas há que se buscar preveni-los. Nesse sentido, a Declaração Universal de Direitos Humanos estabelece um padrão ético e de moralidade, e um marco normativo a partir do qual os Estados-partes devem promover normas para a proteção, melhores condições de vida, trabalho digno e salários justos, da pessoa com deficiência.

\section{POLÍticas PÚBLICAS E AÇÕES AFIRMATIVAS PARA PESSOAS COM DEFICIÊNCIA}

As políticas públicas são ferramentas de atuação do Estado para que os deveres impostos a este pela Constituição sejam colocados em prática, tendo normalmente caráter coletivo, uma vez que o Estado busca atuar, na maioria das vezes, de forma coletiva buscando atuar de forma isonômica a todos os contemplados por políticas públicas (ZOPONI, 2017).

Nesse sentido, ações afirmativas e políticas têm uma relação direta, sendo aquelas uma espécie destas, e, ainda, ferramentas necessárias para que possa se observar a dignidade da pessoa humana, a igualdade e a inclusão social.

Destaca-se que as ações afirmativas, em um primeiro momento, eram tidas como um mero encorajamento para que os detentores do poder decisório levassem em consideração em suas decisões temas sensíveis como educação e mercado de trabalho. Posteriormente, as ações afirmativas passaram a se relacionar com conceito de igualdade de oportunidades e adoção de cotas para inclusão de minorias em instituições de ensino e mercado de trabalho. Em um terceiro 
momento, ações afirmativas passam a serem vistas como políticas públicas e privadas que de forma compulsória, voluntária ou facultativas visam combater a discriminação ou corrigir discriminações sofridas no passado (GOMES, 2001). Este último conceito de ações afirmativas condiz com o de Menezes (2001) e de Maciel e Pitta (2016), que as definem como sendo a forma de trazer minorias a benefícios antes negados pois estas sofriam de discriminação, sendo forma de inclusão.

Ainda, para alguns autores as ações afirmativas constituem mecanismos de busca pela igualdade real entre as pessoas, nas situações em que a própria sociedade em que os grupos discriminados estão inseridos, não alcança, por si mesma, um nível de maturidade para manter suas relações interpessoais pautadas pela igualdade real, sem discriminações (BAEZ et. Al., 2017).

Fato é que se tratando de políticas públicas e ações afirmativas, o Estado mostra-se como de fundamental importância em sua aplicabilidade. Normativas e incentivos a seu respeito, são fator essencial para que haja sua efetividade.

\subsection{HISTÓRICO LEGISLATIVO E AS POLÍTICAS PÚBLICAS PARA AS PESSOAS COM DEFICIÊNCIA}

A deficiência é um fenômeno global, frequentemente associado à pobreza, com impactos políticos, econômicos, culturais, sociais e implicações para a sociedade como um todo. Segundo dados da Organização Mundial da Saúde - OMS (2011), estima-se que 15\% da população mundial possui algum tipo de deficiência. Conforme os dados do Censo do IBGE de 2010 há no Brasil cerca de 45,6 milhões de pessoas com deficiência, o que corresponde a $23,91 \%$ da população brasileira.

A partir dos anos 60, houve uma politização do tema da deficiência, capitaneada por ativistas e organizações de pessoas com deficiência ao redor do mundo, o que resultou em maior visibilidade e importância da questão para os agentes políticos e para a sociedade em geral. Isso gerou a necessidade de mudanças estruturais em relação as políticas públicas voltadas as pessoas com deficiência, em que as medidas assistencialistas tiveram que ser revistas e modificadas (BRASIL, 2016).

As iniciativas voltadas a inclusão da pessoa com deficiência no Brasil se intensificaram após debates iniciados na década de 1980, apesar de que, desde o século XIX, o Brasil já possuía escolas para pessoas com deficiência, sendo que foi o primeiro país na América Latina a criar o Instituto dos Meninos Cegos e o Imperial Instituto dos Surdos-Mudos. Dentre os fatos que 
intensificaram o debate nesse período, podemos enfatizar o ano de 1981, em que a ONU considerou o ano internacional das pessoas com deficiência, movimento com visibilidade mundial que frisou a importância para oportunidades de acesso aos bens e serviços e a inclusão social desse grupo historicamente discriminado (LANNA JUNIOR, 2010). Aliado a isso, podese citar a nova fase de democratização que se iniciava no Estado Brasileiro na década de oitenta, que naturalmente culminou em um emaranhado de direitos que surgiram e foram postulados.

Com a promulgação da Constituição de 1988, o assunto foi definitivamente inserido no marco legal, de forma abrangente e transversal. No Capítulo II da Constituição, que trata dos Direitos Sociais, o inciso XXXI do art. $7^{\circ}$ proíbe qualquer discriminação no tocante a salário e critérios de admissão do trabalhador com deficiência. O art. 23, inciso II, prevê que é competência comum da União, dos Estados, do Distrito Federal e dos Municípios tratarem da saúde e assistência pública, da proteção e da garantia dos direitos das pessoas com deficiência. $\mathrm{O}$ art. 24, inciso XIV, define que é competência da União, dos Estados e do Distrito Federal legislar concorrentemente sobre a proteção e integração social das pessoas com deficiência. A reserva de percentual de cargos e empregos públicos para pessoas com deficiência é tratada no art. 37 .

Na seção dedicada à Saúde, o texto constitucional define saúde como um direito de todos e dever do Estado e garante o acesso universal e igualitário às ações e serviços para sua promoção, proteção e recuperação. Os termos "habilitação" e "reabilitação" das pessoas com deficiência surgem na seção da Assistência Social, art. 203, assim como a promoção de sua integração à vida comunitária. Essa seção trata ainda do benefício de um salário mínimo mensal para as pessoas com deficiência que comprovem não possuir meios de prover a própria manutenção, ou de tê-la provida por sua família. Nesse sentido, a Constituição de 1988 trouxe direitos básicos e essenciais foram formalizados, mas medidas de caráter assistencialista foram mantidas. Esse viés assistencialista esteve bastante presente nas políticas públicas brasileiras e ainda persiste em algumas áreas. Entretanto, paulatinamente, essa visão tem sido substituída por maior valorização da autonomia e independência da pessoa com deficiência.

$\mathrm{Na}$ seção sobre Educação, art. 208, é garantido o atendimento educacional especializado às pessoas com deficiência, preferencialmente na rede regular de ensino. A criação de programas de prevenção e atendimento especializado bem como de integração social do adolescente com deficiência, mediante o treinamento para o trabalho e a convivência, e a facilitação do acesso aos bens e serviços coletivos, com a eliminação de preconceitos e 
obstáculos arquitetônicos, são tratados na Seção da Família, da Criança, do Adolescente e do Idoso, art. 227. Ainda nesse artigo, a Constituição remete à regulamentação posterior a elaboração de normas de construção dos logradouros e dos edifícios de uso público e de fabricação de veículos de transporte coletivo, a fim de garantir acesso adequado às pessoas com deficiência. A partir de então, diversas normas regulamentadoras sobre pessoas com deficiência foram editadas.

Com o reconhecimento de todos esses direitos após redemocratização do Estado Brasileiro, foi possível o reconhecimento dos direitos das pessoas com deficiência (PCD) com caráter de interesse público e não mais como preocupação meramente familiar, culminando assim, na primeira lei que trata do apoio as pessoas com deficiência, em 1989. Trata-se da Lei 7.853, que dispõe sobre o apoio às pessoas com deficiência, integração social e sobre a Coordenadoria Nacional para a Integração da Pessoa Portadora de Deficiência - CORDE.

Porém, na prática a CORDE somente foi implantada em 1993 e tendo como finalidade a elaboração de planos e projetos, voltados para implementação da Política Nacional para Integração das Pessoas Portadora de Deficiência. Em 2003, com o intuito de alcançar a efetividade, foi vinculada à Presidência da República, dentro da pasta de Direitos Humanos. Em 2009, a CORDE foi elevada à condição de Subsecretaria Nacional, para vir a alcançar o status de Secretaria Nacional em 2009.

Com o paradigma de inclusão, que na Constituição pró́be tanto a discriminação em termos de salário quanto em termos de critérios de admissão de PCD, surge a Lei ${ }^{\circ}$ 8.112/90, a qual, no seu art. $5^{\circ}$, estabeleceu o direto das pessoas com qualquer tipo de deficiência se inscreverem em concursos públicos, e concorrerem com igualdade de condições, sendo-lhes reservados $20 \%$ das vagas. No ano seguinte, a Lei $\mathrm{n}^{\circ} 8.213 / 91$ passou a estabelecer, no seu art. 93, que as empresas privadas com mais de 100 funcionários deveriam destinar uma percentagem de vagas para pessoas reabilitadas ou com deficiência, sendo estabelecido o percentual que varia de $2 \%$ a $5 \%$.

Com a Lei n ${ }^{\circ} 8.213$, o papel de inclusão social desse grupo não é somente função do ente Estatal, mas também da sociedade, ao passo que atribui às empresas não só a função de gerar riquezas de ordem econômica, mas a função de desempenhar práticas organizacionais com compromisso éticos e sociais, gerando a diminuição das desigualdades sociais, provenientes das diferenças humanas, tais quais as deficiências, já que nas empresas os funcionários não devem ser excluídos por limitações individuais (SASSAKI, 1997). 
Em 1993, a Lei n 8.742 instituiu o benefício de prestação continuada. Posteriormente, foi alterada pela Lei $\mathrm{n}^{\circ} 12.470 / 2011$, que permitiu a continuidade do pagamento do benefício suspenso por ingresso no mercado de trabalho, caso a relação trabalhista viesse a ser extinta. Tal regulamentação mostrou-se motivo de incentivo às pessoas com deficiência ingressarem no mercado de trabalho sem ficarem envolvidas pelo medo de perder o benefício de prestação continuada, caso o contrato de trabalho fosse interrompido.

Já em meados de 1994, a Lei no 8.899 criou o passe livre no sistema de transporte coletivo interestadual às pessoas com deficiência. No ano seguinte, a Lei no 8.989 passou a estabelecer a isenção do Imposto sobre Produtos Industrializados (IPI) na aquisição de veículos automotores a serem utilizados no transporte autônomo de passageiros, bem como para o uso de pessoas com deficiência física.

Com a entrada em vigor do Decreto $n^{\circ} 3.298 / 99$, que regulamentou a Lei $n^{\circ}$ 7.853/1989, estabelecendo o CONADE como órgão superior de deliberação coletiva com a atribuição principal de garantir a efetivação da Política Nacional de Integração da Pessoa Portadora de Deficiência. O órgão foi criado com o objetivo de não somente acompanhar, mas, também de zelar pela efetivação do sistema descentralizado, elaborar pesquisas, campanhas de prevenção. E também, devido à importância do trabalho, o programa tem a função de acompanhar e avaliar o processo de inclusão das PCD no mercado de trabalho. Denota-se que fora a primeira forma de fiscalização das cotas destinadas as pessoas com deficiência no mercado de trabalho. Além de promover os direitos e aprovar o plano de ação anual da CORDE.

No ano 2000, a Lei $\mathrm{n}^{\mathrm{o}} 10.048$ dispôs sobre o atendimento prioritário e a acessibilidade nos meios de transportes e estabeleceu penalidades em caso do seu descumprimento. No mesmo ano, verificou-se a necessidade de subdividir o assunto de acessibilidade ao meio físico e aos meios de transportes, foi então que a Lei n. ${ }^{\text {o }}$ 10.098/2000 subdividiu o assunto em acessibilidade ao meio físico, aos meios de transporte, na comunicação e informação e em ajudas técnicas.

No que tange à acessibilidade, o Decreto n. ${ }^{\circ}$ 5.296/2004 regulou as Leis 10.048 e 10.098, ampliou o tema a espaços mobiliários e equipamentos urbanos, edificações, serviços de transporte e dispositivos, sistemas e meios de comunicação e informação. Em 2002, com a Lei $n^{\circ} 10.436 / 2002$, foi instituída a Língua Brasileira de Sinais (LIBRAS), que possibilitou a comunicação padronizada em todo o país.

Em 2005, com o advento da Lei $n^{\circ} 11.126$, as pessoas com deficiência visual 
passaram a ter o direito de ingressar e permanecer em ambiente de uso coletivo acompanhado de cão-guia. Dois anos depois, entrou em vigor a Lei $n^{\circ} 11.520 / 2007$, que trata sobre o direito das pessoas om hanseníase receber pensão especial, pois, no passado, tais grupos foram submetidos a isolamento e internação compulsória.

Os anos subsequentes foram de fundamental importância para dar visibilidade nacional aos problemas enfrentados pelas pessoas com deficiência, haja vista que, com o Decreto Legislativo ${ }^{\circ}$ 186/2008 e o Decreto ${ }^{\circ}$ 6.949/2009, a Convenção sobre os Direitos da Pessoa com Deficiência, das Nações Unidas, foi ratificada e promulgada no Brasil com equivalência à de emenda constitucional.

Quando a Convenção dos Direitos da Pessoa com Deficiência foi introduzida no ordenamento jurídico brasileiro com força de norma constitucional, teve-se uma preocupação com a real inclusão, com força de norma constitucional, o sentido das terminologias "deficientes", "portador de deficiência", "portadores de necessidades especiais", foram alteradas para "pessoas com deficiência", que busca destacar a pessoa em primeiro lugar e demarca a importância e as barreiras que limitam a plena inclusão.

Desde a Constituição de 1988, diversas políticas públicas foram adotadas em prol da inclusão das pessoas com deficiência, a fim de garantir o direito de acesso nos mais diversos espaços sociais e também reduzir o preconceito em face de tal grupo.

Com o objetivo de intensificar as políticas públicas que já estavam sendo desenvolvidas, bem como criar novas iniciativas a serem desenvolvidas pelo governo, o Decreto $n^{\circ} 7.612 / 2011$ editou o Plano Nacional dos Direitos da Pessoa com deficiência - Viver sem Limite. Tal plano tem a participação de 15 ministérios e a participação do Conselho Nacional dos Direitos da Pessoa com Deficiência (CONADE), com contribuições da sociedade civil. O Plano Viver Sem Limites visa oportunizar o acesso das pessoas com deficiência a direitos básicos como transporte, saúde, educação moradia, mercado de trabalho e qualificação profissional.

Segundo os dados do Portal da Pessoas com Deficiência, desde a criação do Plano Viver sem Limites até o ano de 2014, foi previsto o investimento de 7, 6 milhões de reais para as pessoas com deficiência. Para esse público, o governo federal articulado com outros programas federais englobou uma séria de ações em áreas como a saúde educação, qualificação profissional, acessibilidade e inclusão social. Sendo que das ações desenvolvidas pelo plano, na educação pode-se citar a ampliação do acesso de crianças e adolescentes com deficiência 
nas escolas; aquisição de 2,6 mil ônibus adaptados para transporte escolar; implantação de 17 mil novas salas e aulas e atualização de 28 mil salas de recursos multifuncionais em escolas públicas regulares e especiais. E também, a contratação de 648 professores de libras, 648 tradutores para instituições federais de ensino, 5\% das vagas do Pronatec, com criação de 150mil vagas que são destinadas a PCDS até 2014, adequações físicas em 42 mil escolas públicas, bolsa de formação cursos e formação profissional técnica de nível médio, curso de formação inicial e continuado, benefícios como cursos gratuitos, alimentação transporte e material didático.

Quanto à saúde o Plano Viver sem Limites regularizou o teste do pezinho em todos os estados, criou 45 centros de reabilitação (física, auditiva, visual, intelectual), proporcionou o aumento em $20 \%$ de financiamento do SUS para 420 Centros Especializados em Odontologia para atender PCD, bem como a qualificação de 6 mil equipes de saúde bucal. Com o plano foi possível a alteração do Programa Minha Casa Minha vida, ode as construções das moradias são adaptadas contando com acessibilidade.

Já em 2015, a Lei nº 13.146 institui a Lei Brasileira de Inclusão da Pessoa com Deficiência (Estatuto da Pessoa com Deficiência). Na prática, foram efetivados os direitos que a Convenção da Pessoa com Deficiência já definia em 2008. Nos dois anos subsequentes, foi criado o Decreto 8.954, que estabelece as competências do Comitê de Inclusão da Pessoa com Deficiência, bem como, a avaliação unificada das mesmas. O Comitê está sob a coordenação da Secretaria Especializada nos direitos das Pessoas om Deficiência, e tem como finalidade a avaliação biopsicossocial da deficiência e criar o Cadastro Nacional de Inclusão de pessoas com deficiência. Dividido em subcomitê de modelo de avaliação unificada e cadastro de inclusão.

Em se tratando de orçamento para pessoas com deficiência, as Leis Orçamentárias Anuais (LOA) de 2000 a 2018 disponibilizaram para programas de Assistência à Pessoa com deficiência, como educação, qualificação, acessibilidade, inclusão e benefícios de prestação continuada mensal vitalícia, $\mathrm{R} \$ 235.707 .183 .844,00$ (duzentos e trinta e cinco bilhões, setecentos e sete milhões, cento e oitenta e três mil, oitocentos e quarenta e quatro reais) nesses 18 anos, representando assim, $0,66 \%$ do orçamento total do período que foi de $\mathrm{R} \$$ 35.940.623.462.095,00 (trinta e cinco trilhões, novecentos e quarenta bilhões, seiscentos e vinte e três milhões, quatrocentos e sessenta e dois mil e noventa e cinco reais).

Ainda, deste valor, apenas em 5 dos 18 anos analisados houve redução da representatividade sobre o orçamento total da união, sendo eles 2003, 2004, 2014, 2015 e 2017. 
Em se tratando em números totais, apenas no ano de 2004 houve redução de valores destinados a assistência à pessoa com deficiência, nesse mesmo ano a representatividade sobre o orçamento geral da união foi de apenas $0,01 \%$, bem abaixo da média dos 18 anos analisados que foi $0,66 \%$. No período analisado o valor orçado para assistência à pessoa com deficiência, considerando uma população média 43.505 .467 , foi de aproximadamente $\mathrm{R} \$ 5.417,88$ por pessoa ao ano.

Cabe destacar que deste orçamento, as LOA detalham diversos programas e ações que visam o atingimento de determinados objetivos. Em se tratando de programas e ações relativas a mercado de trabalho, desde o ano 2000 houve onze programas que se relacionavam ao tema, trazendo como um deu seus objetivos, ações ou como indicadores de controle. Esses programas se relacionam especialmente a qualificação, profissionalização, defesa de direitos, proteção e fiscalização de leis trabalhistas. Ainda, tais programas possuem ações e indicadores que podem ser abertos para atendimento do objetivo do programa, mas em alguns casos agrupam diversas minorias na mesma ação (pessoas com deficiência, afrodescendentes, indígenas, quilombolas, etc.), desse modo os valores referentes a cada minoria especificada não são diferenciados. Para fins desse estudo, considerou-se o valor total do programa ou ação, quando este não separa os valores referentes a pessoas com deficiência e demais minorias.

De 2000 a 2018 foram disponibilizados para programas voltados a pessoas com deficiência e mercado de trabalho $\mathrm{R} \$$ 15.165.969.084,00 (quinze bilhões, cento e sessenta e cinco milhões, novecentos e sessenta e nove mil e oitenta e quatro reais); no entanto, no ano de 2015, houve destinação de pouco mais de 8 bilhões de reais para o programa 2031 - Educação Profissional e Tecnológica que abrange diversas minorias além das pessoas com deficiência, como quilombolas, indígenas, afrodescendentes, mulheres de baixa renda, população do campo, etc., não fazendo distinção orçamentária entre elas, acabando por elevar o montante no período analisado. Reforça-se que nos anos de 2003, 2016, 2017 e 2018 não houve programas relacionados a pessoa com deficiência e o mercado de trabalho.

Tal valor, considerando a população em idade econômica ativa de pessoas com deficiência de 2010 como sendo 42.146 .647 (CENSO, 2010), houve no período de 18 anos analisados valor de $\mathrm{R} \$ 359,84$ por pessoa com deficiência em idade economicamente ativa destinados a pessoa com deficiência e mercado de trabalho. Ou seja, em torno de R $\$ 19,99$ por ano por pessoa com deficiência em idade economicamente ativa.

3.2 A INSERÇÃO DA PESSOA COM DEFICIÊNCIA NO MERCADO DE TRABALHO BRASILEIRO

Revista do Direito do Trabalho e Meio Ambiente do Trabalho | e-ISSN: 2525-9857 | Goiânia | v. 5 | n. 1 | p. 17 - 36 | Jan/Jun. 2019. 
Apesar das medidas e verbas disponibilizados no Brasil para combater a discriminação e desigualdade tanto na sociedade como no mercado de trabalho, ainda se apresentam no Brasil tais problemas, fatos comprovados com os dados apresentados pelo Censo do IBGE (2010) eo Relatório Anual de Informações Sociais (RAIS) de 2016.

A taxa de ocupação de pessoas sem deficiência (PSD) mostra-se maior em todas as faixas etárias analisadas. A partir dos 10 anos, a taxa de ocupação de pessoas com deficiência mostra-se como sendo 46,21\% enquanto pessoas sem deficiência apresentam um número de $55,98 \%$ (IBGE, 2010).

Outro fator importante para avaliação é a remuneração, que se mostra abaixo da remuneração de pessoas com deficiência, sendo que para tal minoria 46,36\% ganham de zero até 1 salário mínimo, enquanto que as pessoas com deficiência esse número diminui para 37,09\%. Nas faixas salariais maiores que 01 (um) salário mínimo o percentual de pessoas sem deficiência é maior que as PCD em todas as faixas salariais (IBGE, 2010).

Ainda no tema remuneração, o RAIS (2016) mostra dados de remuneração média por nível de escolaridade de PCD e pessoas sem deficiência em 31/12/2016. A remuneração de PCD é em média 7,79\% menor que a remuneração das pessoas sem deficiência, mesmo se comparada ao mesmo nível de escolaridade. Apenas em 3 das 9 categorias de escolaridade a remuneração das PCD é maior.

Outra análise importante refere-se à quantidade de vagas de emprego de PCD e PSD, disponibilizada pelo RAIS (2016). O nível de empregabilidade da pessoa com deficiência no ano de 2016 aumentou 3,79\% em relação ao ano de 2015, sendo que no mesmo período, tal índice para PSD teve uma retração de 4,23\%.

O RAIS (2016) traz ainda dados relativo à lei de cotas e seu atendimento. Em 2016, havia no Brasil 17.724.852 de empregos em empresas maiores que cem funcionários, de forma que, para o atendimento da lei deveria haver um total de 724.367 de pessoas com deficiência empregadas; apesar disso, havia apenas 361.050 PCD empregados, havendo assim um total de 363.317 vagas em aberto para PCD.

Na administração pública não há obrigatoriedade da contratação de PCD. No entanto, a Lei $\mathrm{n}^{\circ}$ 8.112/90 reserva $20 \%$ das vagas de concursos públicos a PCD e, apesar disso, havia em 2016, conforme o RAIS (2016), apenas 0,33\% dos cargos de empregados da administração pública ocupados por PCD.

No Brasil, ações afirmativas para pessoas com deficiência vêm sendo debatidas desde 
a década de 1960, mas tomaram maior corpo a partir da Constituição de 1988, que foi o estopim para uma série de medidas que tinham como objetivo a inclusão e a igualdade real da pessoa com deficiência na sociedade.

Nesse sentido, os valores disponibilizados no orçamento público da União para assistência à pessoa com deficiência vêm crescendo ano a ano, mostrando que o governo vê tal tema com cada vez mais importância. Por outro lado, os valores referentes à pessoa com deficiência no mercado de trabalho têm se mostrado cada vez menos importantes. Há no orçamento da união recursos destinados a tal tema; no entanto, não há preocupação em detalhálos, agregando-lhes orçamentos próprios, mas sim de uni-los às demais minorias, ou ainda não destinar valor algum ao referido tema, como nos anos de 2016, 2017 e 2018.

Apesar das ações afirmativas adotadas no país e das evoluções que têm se tido no mercado de trabalho para a pessoa com deficiência, ainda há que evoluir em diversos pontos. A escolaridade e ocupação de PCD mostram-se ainda inferiores que de PSD. A remuneração mostra-se em média 7,79\% menor para PCD que PSD, mesmo em faixas de escolaridades iguais.

Ainda, mesmo com a evolução do número de empregos para PCD, de 2015 para 2016, a lei de cotas ainda está longe de ser atingida em sua totalidade. Havia, em 2016, 363.317 vagas em aberto, tendo uma efetividade da lei de apenas $49,84 \%$.

Porém, mesmo com as dificuldades, as ações afirmativas mostram-se papel importante para inclusão e redução de desigualdade e discriminações, sem elas o cenário estaria pior. O que é possível afirmar é que tais medidas precisam ser cada vez mais apoiadas e assegurar sua aplicação e sua efetividade.

\section{CONSIDERAÇÕES FINAIS}

Ao realizar a pesquisa, inevitavelmente se faz necessária abordagem da Constituição Federal, a qual, na busca de efetivar e consolidar os direitos humanos, dá status constitucional aos direitos e garantias fundamentais reconhecidos internacionalmente, medida essa essencial para incorporar tratados internacionais.

A humanidade de maneira geral passou e passa por período de conscientizações em relação às injustiças sociais que permeiam o dia a dia. A premissa que sustenta a necessidade de ações positivas é a de que determinados grupos da população continuam a sofrer com a discriminação e a exclusão social.

É preciso compreender que não é a limitação que vai determinar a deficiência, mas 
sim, as barreiras que existem nos espaços, como, meio físico, transporte, ausência de informações, na prestação de serviços, entre outras.

Por esses e outros motivos é que o Estado ratificou convenções e tratados internacionais assumindo a obrigação de garantir as pessoas com deficiência, a igualdade de oportunidades entre indivíduos com e sem deficiências, na busca dos direitos e garantias fundamentais, como pleno emprego, justo salário, igualdade de condições, dignidade da pessoa, educação, liberdade, entre outras.

Por todos os documentos internacionais analisados, percebe-se que são incisivos e até mesmo repetitivos na questão do pleno exercício dos seres humanos, de seus direitos individuais, da não discriminação, na promoção de justiça social, do pleno emprego, as liberdades, à promoção da igualdade e dignidade da pessoa humana, justiça social, sem qualquer distinção, ou por qualquer motivo que seja.

No Brasil, ações afirmativas para pessoas com deficiência vêm sendo debatidas desde a década de 1960, mas tomaram maior corpo a partir da Constituição de 1988, que foi o estopim para uma série de medidas que tinham como objetivo a inclusão e a igualdade real da pessoa com deficiência na sociedade.

Apesar das ações afirmativas adotadas no país e das evoluções que têm se tido no mercado de trabalho para a pessoa com deficiência, ainda há que evoluir em diversos pontos. A escolaridade e ocupação de PCD mostram-se ainda inferiores que de PSD. A remuneração mostra-se em média 7,79\% menor para PCD que PSD, mesmo em faixas de escolaridades iguais.

Ainda, mesmo com a evolução do número de empregos para PCD, de 2015 para 2016, a lei de cotas ainda está longe de ser atingida em sua totalidade. Havia, em 2016, 363.317 vagas em aberto, tendo uma efetividade da lei de apenas $49,84 \%$.

Porém, mesmo com as dificuldades, as ações afirmativas mostram-se papel importante para inclusão e redução de desigualdade e discriminações, sem elas o cenário estaria pior. O que é possível afirmar é que tais medidas precisam ser cada vez mais apoiadas e assegurar sua aplicação e sua efetividade.

\section{REFERÊNCIAS}

BAEZ, N. L. et al. (Org.). A evolução histórica das ações afirmativas e seu 
desenvolvimento no Brasil. Joaçaba: Unoesc, 2017.

BRASIL. MINISTÉRIO DO TRABALHO E EMPREGO. Relação anual de informações sociais (RAIS). Relatório anual. Brasília: Ministério do Trabalho e Emprego, 2016. Disponível em:

<http://pdet.mte.gov.br/rais>. Acesso em: 15 jun. 2018.

CASADO FILHO, N. Direitos humanos e fundamentais. São Paulo: Saraiva, 2012. GOMES, J. B. O debate constitucional sobre as ações afirmativas. 2001.

Disponível em:

<http://egov.ufsc.br/portal/sites/default/files/anexos/21672-21673-1-PB.pdf>. Acesso em: 12 jul. 2018.

INSTITUTO BRASILEIRO DE GEOGRAFIA E ESTATÍSICA - IBGE. Censo demográfico 2000 .

Características gerais da população: resultados da amostra. Rio de Janeiro: IBGE, 2000.

INSTITUTO BRASILEIRO DE GEOGRAFIA E ESTATÍSICA - IBGE. Censo demográfico 2010.

Características da população e dos domicílios: resultados do universo. Rio de Janeiro:

IBGE, 2011. LANNA JUNIOR, M. C. História do movimento político das pessoas com deficiência no Brasil.

Brasília: Secretaria de Direitos Humanos, 2010.

LINHARES, P. A. Direitos fundamentais e qualidade de vida. São Paulo: Inglu, 2002.

LOBATO, F.; SANTOS, R. E. Ações afirmativas políticas públicas contra as desigualdades raciais. Rio de Janeiro: DP\&A, 2003.

MACIEL, A. S.; PITTA, R. G. Ação afirmativa e liberalismo igualitário: os contributos de Rawls e Dworkin. In: Ximenes, J. et. al. (Org.). Constituição e democracia III: XXV Congresso do Conpedi - Curitiba. Florianópolis: Conpedi, 2016.

MENEZES, P. L. A ação afirmativa (affirmative action) no direito norte-americano.

São Paulo: Revista dos Tribunais, 2001.

ORGANIZAÇÃO MUNDIAL DA SAÚDE - OMS. Relatório mundial sobre a deficiência. 2011. São Paulo: Governo de São Paulo, 2011. Disponível em: $<$ http://www.pessoacomdeficiencia.sp.gov.br/mwginternal/de5fs23hu73ds/progress?id=O11qmv6a0ZF8NMLwl-EIPf7UGbNMpjv7V8ViOPJLis,>. Acesso em: 10 jun. 2018. 
PIOVESAN, F. Direitos humanos e justiça internacional: um estudo comparativo dos sistemas regionais europeu, interamericano e africano. 2.ed. São Paulo: Saraiva, 2011.

REZENDE, R. V. A aplicação da declaração Sociolaboral do Mercosul e a supranacionalidade operativa dos direitos humano. Campinas, Revista do TRT da $15^{a}$ Região, n. 18, mar. 2002.

SASSAKI, R. K. Deficiência psicossocial: a nova categoria de deficiência. Fortaleza: Agenda 2011 do Portador de Eficiência, 2010.

SASSAKI, R. K. Inclusão, construindo uma sociedade para todos. Rio de Janeiro:

WVA, 1997. SEDA, J. A. Discapacidad y derechos: impacto de la convención sobre los derechos de las personas con discapacidad. Buenos Aires: Jusbaires, 2017.

SILVA, S. P. Discriminação positiva: ações afirmativas na realidade brasileira.

Brasília: Brasília Jurídica, 2005.

ZOPONI, V. Elementos morfológicos do direito fundamental à saúde. In: BAEZ, N. L. et al. (Org.). A evolução histórica das ações afirmativas e seu desenvolvimento no Brasil. Joaçaba: Unoesc, 2017. 